\title{
El ejercicio del derecho a la salud en personas mayores en Argentina y Colombia: una aproximación a partir del análisis de la mortalidad por causas sensibles a la atención de la salud en el siglo XXI
}

\author{
Eleonora Rojas Cabrera* \\ Andrés Peranovich ${ }^{* *}$ \\ Doris Cardona Arango ${ }^{\star \star \star}$ \\ Douglas Lizcano Cardona ${ }^{\star \star * *}$
}

\begin{abstract}
A partir de que Argentina y Colombia reconocen la salud como un derecho esencial y se comprometen, entre otras cuestiones, a brindar prestaciones sanitarias para garantizar su ejercicio sin discriminación, se propone indagar, comparativamente, acerca de los desafíos que estos países enfrentan para cumplir con este compromiso en las personas de sesenta años y más. Para ello, se calculan y analizan, para los trienios 2000-2002 y 2013-2015, tasas de mortalidad por causas consideradas sensibles a la atención de la salud según país, sexo y edad, con base en información de la Organización de las Naciones Unidas, y se calculan proporciones específicas sobre encuestas oficiales de cada país. Los resultados evidencian, en ambos países y para el conjunto de causas referidas, una mayor mortalidad en hombres, que crece con la edad hasta los 74 años y con tendencia al descenso, principalmente en Colombia. Un análisis más detallado por causas revela una situación similar en este último caso, a diferencia de Argentina, donde aumenta la mortalidad asociada a enfermedades respiratorias. Independientemente de estas diferencias, las tasas obtenidas al final del período investigado acusan, en los dos países, la necesidad de redoblar los esfuerzos para continuar su reducción (o revertir su incremento), con especial foco en las personas mayores que menos recursos tienen y su valor en tanto ciudadanos con iguales derechos al resto de la población.
\end{abstract}

Palabras clave: Derechos humanos. Personas mayores. Acceso a servicios de salud. Mortalidad por causas sensibles a la atención de la salud. Argentina. Colombia.

\footnotetext{
* Centro de Investigaciones y Estudios sobre Cultura y Sociedad, Universidad Nacional de Córdoba (CIECS - CONICETy UNC), Córdoba, Argentina (eleonorarojascabrera@gmail.com; https://orcid.org/0000-0002-8195-3027).

${ }^{* *}$ Centro de Investigaciones y Estudios sobre Cultura y Sociedad, Universidad Nacional de Córdoba (CIECS - CONICET y UNC), Córdoba, Argentina (andrescpera@gmail.com; https://orcid.org/0000-0002-7639-5091).

${ }^{* \star \star}$ Universidad Corporación para Estudios en la Salud (CES), Medellín, Colombia (dcardona@ces.edu.co; https://orcid. org/0000-0003-4338-588X).

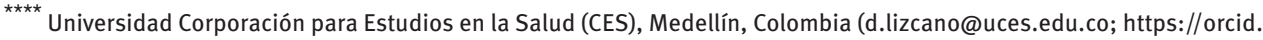
org/0000-0002-1652-3231).
} 


\section{Introducción}

La salud es un derecho humano esencial consagrado en numerosas declaraciones y tratados de derechos humanos. Entre ellos, la Declaración Universal de Derechos Humanos (DUDH) de 1948 (artículo 25) y el Pacto Internacional sobre Derechos Económicos, Sociales y Culturales (PIDESC) de 1966 (artículo 12), instrumentos mediante los cuales los Estados reconocen el derecho de todas las personas al máximo nivel posible de salud y se comprometen a emprender medidas para garantizarlo sin distinción de ninguna índole.

Esto último exige que las medidas se enfoquen en grupos poblacionales considerados especialmente vulnerables a sufrir discriminación en el ejercicio de sus derechos en función de ciertos ejes de desigualdad social. Estos grupos comprenden a las personas mayores, quienes, con frecuencia, son abandonadas y marginadas a casusa de su edad (CEPAL, 2013).

Tal es la vulnerabilidad de las personas mayores que, en 2015, la Organización de los Estados Americanos (OEA) celebró la Convención Interamericana sobre la Protección de los Derechos Humanos de las Personas Mayores (CIPDHPM), mediante la cual reafirmó su derecho al acceso a servicios integrales de protección y promoción de la salud (OEA, 2015). La importancia de que los países adhieran a esta convención radica en la capacidad de este acto para reforzar los marcos legales vigentes en cada uno de ellos, de manera de proteger los derechos de las personas que han alcanzado determinada edad (sesenta años, de acuerdo a su texto) y cuya salud no suele ser atendida apropiadamente por los sistemas de salud.

El compromiso de atender la salud de las personas mayores se retoma con la celebración de conferencias en el ámbito de la Organización de las Naciones Unidas (ONU), que refuerzan las intenciones de los tratados al establecer en sus planes de acción metas para avanzar en el ejercicio de derechos con igualdad de oportunidades. Constituyen ejemplos de estos planes el plan de los Objetivos de Desarrollo Sostenible (ODS) (ONU, 2015), en el mundo, y el Consenso de Montevideo sobre Población y Desarrollo (CM) (CEPAL, 2013), en América Latina y el Caribe, ambos actualmente en vigencia y con metas a alcanzar en 2030. En particular, el ODS 3 establece «Garantizar una vida sana y promover el bienestar de todos a todas las edades», para lo cual plantea, entre otras cuestiones, que los Estados garanticen el acceso universal a servicios de salud de calidad. Por su parte, el CM destina un capítulo completo a las personas mayores, en el que se destaca la necesidad de adaptar las prestaciones de salud a las necesidades específicas de esta población (capítulo C).

Los países de América Latina han adoptado la DUDH y el PIDESC, asumiendo la obligación legal de emprender acciones para garantizar los derechos allí reconocidos. Así también se comprometen a desplegar medidas para alcanzar los ODS de acuerdo con los enunciados del CM. ${ }^{1}$ Sin embargo, a la fecha de publicación de este artículo, solo siete

\footnotetext{
${ }^{1}$ Mientras que los tratados de derechos son instrumentos jurídicamente vinculantes para los países que adhieren a ellos (es decir, que su adopción genera obligaciones legales de acatar las disposiciones contenidas en sus textos), los planes de acción de las conferencias basadas en los derechos reconocidos en los tratados no revisten esta condición.
} 
de ellos han ratificado la CIPDHPM (OEA, s.f.), tratado que se centra en la atención de las personas mayores. Entre estos últimos se encuentra Argentina, ${ }^{2}$ que ratificó el instrumento en 2017 (OEA, s.f.) y que está actualmente en vías de otorgarle jerarquía constitucional (ARGENTINA, 2019).

Otros países, en cambio, si bien no han ratificado hasta el momento la CIPDHPM, sí desplegaron acciones en concordancia con la incorporación de dicho instrumento a su normativa legal. Tal es el caso de Colombia (COLOMBIA, 2019), que, a diferencia de Argentina, establece expresamente en su Constitución Política de 1991 la obligación de proteger y asistir a este grupo poblacional (artículo 46).

En este contexto de similitudes y diferencias desde el punto de vista normativo surge el interés por indagar si Argentina y Colombia evidencian los mismos desafíos para avanzar en el ejercicio del derecho a la salud de las personas mayores, desde el punto de vista de las prestaciones comprometidas para tal fin. Para ello, se propone analizar, comparativamente, el comportamiento de la mortalidad por causas sensibles a la atención de la salud, desde 2000, en la población de sesenta años y más. Estas causas se corresponden con «muertes prematuras que podrían haberse evitado si hubiera habido una atención a la salud oportuna y eficaz» (OPS, 2014, p. 10), de manera que su ocurrencia atenta contra el efectivo ejercicio de derechos reconocidos internacional y nacionalmente. A su vez, su estudio permite identificar «posibles puntos débiles en los servicios de salud» (OPS, 2014, p. 11), ofreciendo así evidencias para ejecutar acciones dirigidas a contrarrestarlas.

\section{Datos y métodos}

Se plantea una investigación sociodemográfica, descriptiva y comparativa entre países, con apoyo en:

- Las estadísticas de mortalidad de Argentina y Colombia, recopiladas y sistematizadas por la Organización Mundial de la Salud (OMS) para los trienios 2000-2002 y 20132015 y desagregadas según sexo, edad y causa de acuerdo con los códigos establecidos en la Clasificación Internacional de Enfermedades-Décima Revisión (CIE-10). Si bien la utilización de esta fuente de información permite, en principio, efectuar comparaciones directas entre países, cabe mencionar algunas cuestiones referidas a la calidad de los datos que se contemplan en cada caso y su posible influencia en los cotejos resultantes y que se vinculan a errores de cobertura y de contenido en los registros de muertes de cada país. Con relación a los primeros, existen evidencias de un subregistro considerablemente mayor de muertes en Colombia que se se materializan, por ejemplo, en el valor de la diferencia relativa entre el número de defunciones informadas por las estadísticas vitales y las estimadas en las proyecciones de población elaboradas por el Centro Latinoamericano y Caribeño de Demografía

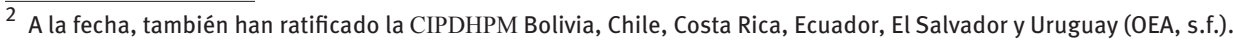


(Celade)-División de Población de la CEPAL para el período 2005-2010, equivalente a $1,6 \%$ y $21,7 \%$ para Argentina y Colombia, respectivamente (CELADE-CEPAL, 2015).

A su vez, entre los errores de contenido merecen especial consideración los asociados a la declaración de la edad de las personas fallecidas, ya sea por su desconocimiento, por la provisión incorrecta por parte del informante de la defunción o por descuido de quien la registra (BAY; ORELLANA, 2007; VILLARROEL-CÁRDENAS, 2018). Así también, los relativos a la consignación de causas consideradas «poco útiles» ${ }^{3}$ a efectos de la salud pública. A pesar de las diferencias en la cobertura del registro de defunciones en detrimento de Colombia, en este país, en 2009, el porcentaje de causas «poco útiles» asciende a 13,7\%, mientras que en Argentina equivale al 39\% en un año cercano (2010) (RIBOTTA, 2014).

Con miras a superar algunas de estas limitaciones se decide aplicar a las defunciones registradas en cada país un factor de corrección que surge del cociente entre las defunciones estimadas por la División de Población de la ONU (Revisión 2019) según sexo y grupo de edad para los períodos 2000-2005 y 2010-2015, y las contempladas en los registros de la oms. Aunque esta investigación se centra en el estudio de ciertas causas de mortalidad, se asume el supuesto de que la distribución de las defunciones no registradas en categorías de causas, por grupo de edad y sexo, es igual que la de las defunciones relevadas en todas las causas (OPS, 2003).

Consideradas las anteriores aclaraciones, cabe agregar, en referencia a los trienios explicitados, que el estudio inicia en el año 2000 (punto de partida del plan antecesor a los ODS; es decir, el plan de los Objetivos de Desarrollo del Milenio) y finaliza en 2015 , último año para el cual se encuentra disponible la información a la fecha de llevarse a cabo. ${ }^{4}$

- Las proyecciones de población por país, sexo y edad de la División de Población de la ONU (Revisión 2019) para los años intermedios a los trienios explicitados (es decir, 2001 y 2014). Teniendo en cuenta que estas proyecciones (al igual que las defunciones estimadas referidas en el punto anterior) se hacen con base en los censos de población, las estadísticas vitales, y, en algunos casos, encuestas específicas, ${ }^{5}$ cabe mencionar que también ven afectada su calidad en virtud de limitaciones de las fuentes de datos involucradas como, por ejemplo, las relativas a problemas asociados

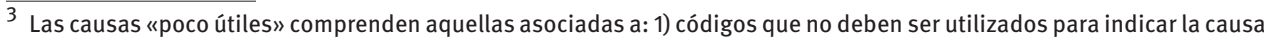
básica de defunción; 2) causas «intermedias» de muerte, asociadas a la causa básica pero no equiparables con esta última; 3) causas «inmediatas» de muerte, igualmente ligadas a la causa básica pero tampoco equivalentes a esta; 4) causas «no especificadas» dentro de un agrupamiento más grande de causas de muerte, y 5) causas de defunción «mal definidas». Para más información, consultar Ribotta (2014).

${ }^{4}$ Aunque en principio se intentó trabajar con las bases oficiales de mortalidad publicadas por los países para sus territorios nacionales (en el ámbito de la Dirección de Estadística e Información de Argentina y el Departamento Nacional de Estadística de Colombia), con datos más actualizados en relación con la OMS, finalmente se decidió desestimar la información. Esta decisión obedeció a que, en Argentina, los datos se difunden en un formato más agregado del requerido para los cálculos que se plantean en el marco de este trabajo, hecho que dificulta comparaciones directas entre países e impide, por lo tanto, dar alcance al objetivo establecido en la introducción.

5 Tales como las Encuestas de Demografía y Salud (DHS, por sus siglas en inglés), llevadas a cabo en algunos países por el programa homónimo financiado por la Agencia de Estados Unidos para el Desarrollo Internacional (USAID, por sus siglas en inglés). Si bien Argentina no forma parte del universo de estudio del programa, Colombia sí lo hace desde 1986 (THE DHS PROGRAM, s.f.).
} 
a la declaración de la edad, el subregistro de nacimientos y defunciones, entre otros (DEL POPOLO, 2000; BAY, 2012). Sin embargo, se decide emplearlas igualmente en función de que se corresponden con información oficial.

- Las bases usuarias de la Encuesta Nacional de Factores de Riesgo (ENFR) de 2005 y 2013 de Argentina, la Encuesta Nacional de Calidad de Vida (ECV) de 2003 y 2013 de Colombia y la Encuesta Longitudinal de Protección Social (ELPS) de 2012 de este último país. Mientras que el primero de estos relevamientos se asocia a una muestra representativa de la población de 18 años y más en aglomeraciones urbanas de cinco mil y más habitantes (ARGENTINA, 2005a, 2014), el segundo y el tercero son representativos del total de población del interior del territorio nacional (DANE, 2014, 2019), de modo que, en principio, no serían estrictamente comparables. Aun así, se decide omitir esta limitación para hacer lecturas comparativas entre países, dada la información que estas fuentes reúnen y su relevancia para el estudio del tema abordado.

A partir de las dos primeras fuentes de información referidas se calculan y analizan tasas de mortalidad (TM) por causas sensibles a la atención de la salud según las desagregaciones detalladas, como el resultado del cociente entre el promedio simple del número de defunciones corregidas (según lo explicitado antes), por trienio, para cada una de ellas, y la población estimada en el año medio de cada trienio. Con relación a este cálculo, cabe aclarar que:

- Para la selección de las causas sensibles a la atención de la salud se emplea la clasificación de la OPS para el estudio de la mortalidad prematura atribuida a estas ${ }^{6}$ (OPS, 2014). El motivo de esta elección, en parte anticipado en la introducción, radica en que se trata de «una opción conveniente para aproximarse al impacto de la atención de la salud sobre la muerte prematura», al tiempo que colabora con la detección de «posibles puntos débiles en los servicios de salud» (OPS, 2014, p. 11), más allá de que no proporciona evidencias sobre la existencia de diferenciales en la atención de la salud eficaz.

- Aunque el foco del trabajo es la población de sesenta años y más, las personas mayores de acuerdo a la OMS (s.f.), a modo de contextualización se presentan, inicialmente, TM para los tramos etarios 0-4, 5-14, 15-24, 25-59 y sesenta años y más, vinculados, respectivamente, a primera infancia, niñez, juventud, adultez y vejez. Posteriormente, la TM de la población de sesenta años y más se desagrega, a su vez, en los tramos de 60-64, 65-69, 70-74 y 75 años y más, ligados en los tres primeros casos a una población que acumula una proporción considerablemente mayor de causas sensibles a la atención de la salud y en el último, a una población en la que el volumen de estas causas se reduce notablemente, de acuerdo con la clasificación utilizada (véase el Cuadro 1 del Anexo).

\footnotetext{
$\overline{6}$ Esta clasificación se encuentra detallada en el Cuadro 1 del Anexo.
} 
- Si bien la OPS recomienda expresar las TM específicas por causas o grupos de causas por cien mil habitantes (OPS-UNIDAD DE INFORMACIÓN; ANÁLISIS DE SALUD, 2015), para este estudio, dados los valores obtenidos, se considera adecuado su expresión por mil habitantes, a efectos de agilizar su lectura e interpretación.

Una vez obtenidas las TM, se calculan algunas proporciones sobre la información resultante de las encuestas referidas a fin de contribuir a la comprensión de su magnitud y dinámica. El detalle de este cálculo se especifica directamente en el apartado destinado a la discusión de los resultados, al momento de presentarse las proporciones en cuestión.

\section{Resultados}

Los resultados obtenidos en primera instancia revelan que los dos países han hecho esfuerzos para atender la salud de la población de todas las edades, con mayor énfasis en los tramos más afectados por la mortalidad por causas sensibles a la atención de la salud, es decir, niños y niñas menores de cinco años y personas de sesenta años y más (Gráfico 1). Estos esfuerzos se han manifestado de diferentes maneras: en Argentina, se han producido mayormente en el primer grupo poblacional (la TM de niños/as menores de cinco años por causas sensibles a la atención de la salud disminuye $27 \%$ y la de la población de sesenta años y más lo hace en un 19\%); mientras que en Colombia se ha hecho más énfasis en el segundo (la TM de niños/as menores de cinco años cae un $24 \%$ y la de personas mayores lo hace un $36 \%$ ).

Con relación específica a la población de sesenta años y más, se destaca que Colombia parte de una TM mayor en comparación con la de Argentina (de 8,1 por mil habitantes de sesenta años y más, en tanto que la TM argentina es de 6,5 por mil habitantes de sesenta años y más), pero logra reducirla en mayor proporción, para llegar a un valor similar aunque levemente inferior- al argentino al final del período analizado (de 5,2 por mil habitantes y de 5,3 por mil habitantes, respectivamente) (Gráfico 1).

El hecho de que las TM por causas sensibles a la atención de la salud para la población de sesenta años y más exhiban mayores valores en comparación con los restantes tramos etarios y de las implicancias de estas muertes a la luz de compromisos asumidos en razón de su posibilidad de ser evitadas amerita un análisis más profundo de su composición y comportamiento. A pesar de que por las causas referidas la TM continúa exhibiendo valores máximos al final del período investigado, su comportamiento decreciente deriva en una menor participación relativa de las muertes que contempla en el total de las muertes consideradas en cada trienio. Es así que, en Argentina, en el período 2000-2002, el peso relativo de este grupo de causas es igual a 15\% (valor ligado a 97.491 de un total de 660.314 defunciones), mientras que, en el trienio 2013-2015, este se reduce al 13\% (100.058 defunciones de un total de 748.858). En Colombia, la participación relativa de estas muertes varía de $23 \%$ (76.423 defunciones de un total de 337.261 defunciones relevadas) a $18 \%$ (81.791 defunciones de un total de 463.666) durante el mismo período. Si bien la variación 
de este indicador arroja siempre menores valores en Argentina, debe destacarse que los esfuerzos (en términos de su reducción) son mayores en el caso colombiano: en efecto, la reducción en el primero de estos países es del $2 \%$ mientras que en el segundo, del $5 \%$.

GRÁFICO 1

Tasa de mortalidad por causas sensibles a la atención de la salud, según grupo de edad Argentina y Colombia - 2000-2015

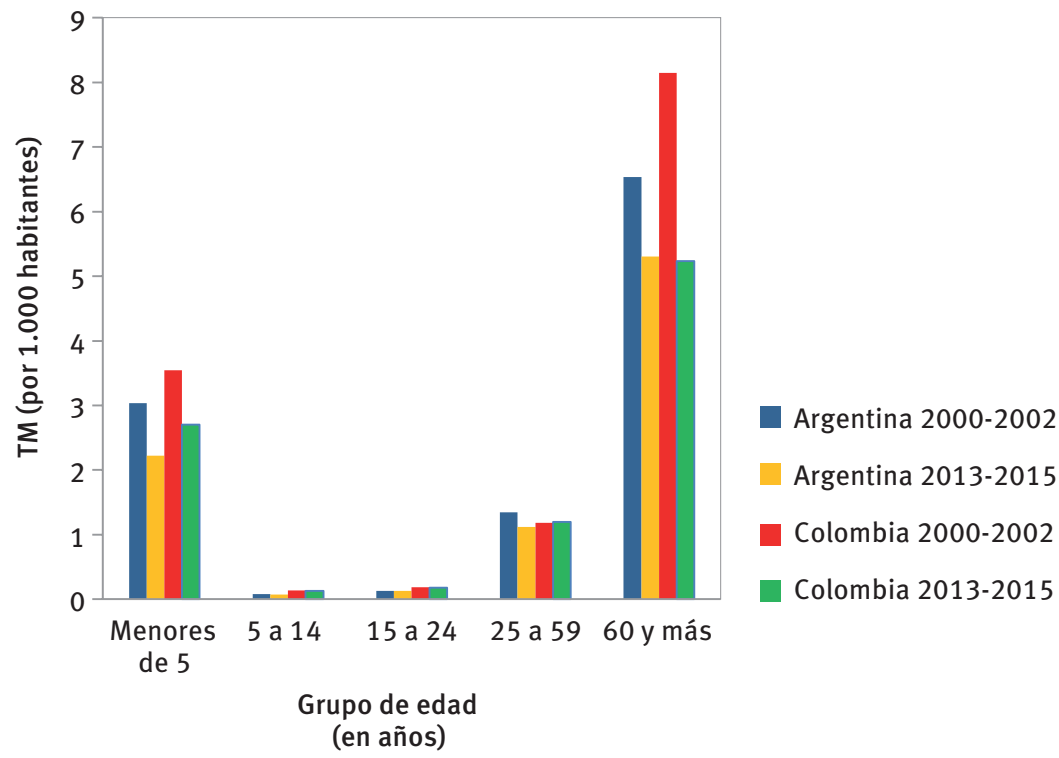

Fuente: Elaboración propia con base en información proveniente de la OMS y la División de Población de la ONU.

El desglose de la TM por edad y sexo muestra, para la población de 60 a 74 años, que la mortalidad aumenta con la edad, sobre todo en hombres. Aun así, esta se reduce en todos los grupos etarios analizados, con mayor énfasis en Colombia, principalmente en mujeres. A partir de los 75 años, los valores de la TM, más similares entre sexos, son inferiores a los de las poblaciones más jóvenes (cuestión ligada a la considerable menor cantidad de causas entendidas como sensibles a la atención de la salud), levemente superiores en Argentina y tienden a mantenerse constantes prácticamente en todos los casos (Tabla 1)

La variación de cada TM impacta diferencialmente en la participación relativa de las muertes analizadas en el total de muertes por trienio. Si bien entre los hombres de Argentina de 60 a 74 años la TM se reduce, aumenta su peso relativo, a la vez que, en las mujeres de este país, este peso supera al de los hombres pero disminuye acompañando la dinámica de la TM vinculada. En Colombia se registra una situación similar, aunque asociada a mayores TM (Tabla 2).

En la población de 75 años y más, la participación relativa de estas muertes se mantiene por debajo del $0,4 \%$, con independencia del país, sexo y período (Tabla 2 ). 
TABLA 1

Tasa de mortalidad de la población de sesenta años y más por causas sensibles a la atención de la salud, según sexo y grupo de edad

Argentina y Colombia - 2000-2015

\begin{tabular}{lcccc}
\multicolumn{1}{c}{ Sexo y trienio } & \multicolumn{4}{c}{ Grupo de edad } \\
\cline { 2 - 4 } & $\mathbf{6 0 - 6 4}$ & $\mathbf{6 5 - 6 9}$ & $\mathbf{7 0 - 7 4}$ & $\mathbf{7 5 +}$ \\
\hline Argentina & & & & \\
Hombres, 2000-2002 & 7,5 & 11,4 & 18,1 & 0,2 \\
Hombres, 2013-2015 & 6,4 & 9,8 & 15,4 & 0,3 \\
Mujeres, 2000-2002 & 4,6 & 6,8 & 10,7 & 0,2 \\
Mujeres, 2013-2015 & 3,8 & 5,7 & 8,7 & 0,2 \\
\hline Colombia & & & & 0,0 \\
Hombres, 2000-2002 & 7,4 & 11,4 & 19,8 & 0,0 \\
Hombres, 2013-2015 & 5,0 & 8,3 & 14,7 & 0,0 \\
Mujeres, 2000-2002 & 6,1 & 9,7 & 16,3 & 0,0 \\
Mujeres, 2013-2015 & 3,7 & 6,0 & 10,6 & \\
\hline
\end{tabular}

Fuente: Elaboración propia con base en información proveniente de la OMS y la División de Población de la ONU.

TABLA 2

Participación de las causas sensibles a la atención de la salud en el total de muertes relevadas em la población de sesenta años y más, según sexo y grupo de edad

Argentina y Colombia -2000-2015

En porcentaje

\begin{tabular}{lcccc}
\hline \multirow{2}{*}{ Sexo y trienio } & \multicolumn{4}{c}{ Grupo de edad } \\
\cline { 2 - 5 } & $\mathbf{6 0 - 6 4}$ & $\mathbf{6 5 - 6 9}$ & $\mathbf{7 0 - 7 4}$ & $\mathbf{7 5 +}$ \\
\hline Argentina & & & & \\
Hombres, 2000-2002 & 35,0 & 36,1 & 36,7 & 0,2 \\
Hombres, 2013-2015 & 36,6 & 36,8 & 38,0 & 0,3 \\
Mujeres, 2000-2002 & 45,0 & 43,7 & 42,5 & 0,3 \\
Mujeres, 2013-2015 & 43,5 & 42,8 & 42,0 & 0,3 \\
\hline Colombia & & & & \\
Hombres, 2000-2002 & 46,8 & 49,0 & 49,8 & 0,1 \\
Hombres, 2013-2015 & 48,1 & 49,2 & 50,2 & 0,1 \\
Mujeres, 2000-2002 & 53,6 & 53,5 & 54,3 & $0,0^{\star}$ \\
Mujeres, 2013-2015 & 52,0 & 52,1 & 53,1 & 0,1 \\
\hline
\end{tabular}

Fuente: Elaboración propia con base en información proveniente de la OMS y la División de Población de la ONU.

$\left.{ }^{*}\right)$ Representa un valor inferior a $0,1 \%$.

Un análisis más detallado de las causas muestra que, en la población de 60 a 74 años de los dos países, la mayor parte de las defunciones se debe a enfermedades del sistema circulatorio - que en el trienio 2000-2002 representan cerca del 50\% y del $63 \%$ de las defunciones por causas sensibles a la atención de la salud en Argentina y Colombia, respectivamente-. Sin embargo, la TM por estas causas decrece, nuevamente, con mayor intensidad en Colombia, más allá de que registre un valor comparativamente superior al argentino al final del período analizado (Tabla 3). La variación de la TM atribuida a este grupo de causas se da principalmente en función de su descenso por enfermedades isquémicas del corazón y por enfermedades cerebrovasculares, aterosclerosis y enfermedad periférica no especificada, causas más frecuentes al interior de la categoría. 
A este subgrupo de causas le suceden, en orden de relevancia, los tumores (neoplasias), con TM también decrecientes (también con mayor intensidad en Colombia), pero con participación creciente (aproximadamente 25\%) (Tabla 3). Intervienen en la reducción de esta TM la caída de la mortalidad por tumores malignos del aparato digestivo (los más habituales en ambos países) seguida de la atribuida a tumores malignos de la mama femenina (solo en Argentina) y a tumores malignos de cuello del útero (solo en Colombia).

Por otro lado, la estructura de la mortalidad difiere entre países. En Argentina, siguen, consecutivamente en razón de su participación relativa, las muertes por ciertas enfermedades infecciosas y parasitarias (con peso relativo equivalente al $10 \%$ al inicio del período investigad o y con TM decreciente, fundamentalmente dada la reducción de la TM por lepra, tétanos, septicemia y otras enfermedades bacterianas), sucedidas de las enfermedades del sistema respiratorio ( $7 \%$; con TM creciente, mayormente por aumento de la TM por neumonía), enfermedades del sistema genitourinario (6\%), enfermedades del sistema digestivo ( $3 \%$ ) y, al final, las restantes causas (1\%). La TM asociada a estos tres últimos grupos de causas mantiene constante su valor (Tabla 3).

Por su parte, en Colombia, las muertes por enfermedades del sistema respiratorio, enfermedades del sistema digestivo y ciertas enfermedades infecciosas y parasitarias se distribuyen en proporción similar cercana al 4\% cada una en el trienio 2000-2002. Inciden en menor medida las muertes por enfermedades del sistema genitourinario (3\%) y las restantes causas (1\%). Respecto de la variación de las TM vinculadas, en la mayor parte de los casos se observa una tendencia al descenso (Tabla 3). En esta reducción llama la atención la caída de la TM por asma (que, a diferencia de la neumonía como causa respiratoria más común, mantiene su TM constante), por úlceras del estómago y duodeno, por trastornos de la vesícula biliar y de las vías biliares del páncreas (como causas de muerte más comunes entre las enfermedades digestivas) y por tuberculosis en el grupo de las infecciosas y parasitarias.

TABLA 3

Tasa de mortalidad de la población de 60 a 74 años por causas seleccionadas sensibles a la atención de la salud Argentina y Colombia - 2000-2015

Por mil habitantes

\begin{tabular}{lccccc}
\hline \multirow{2}{*}{ Causas } & \multicolumn{2}{c}{ Argentina } & & \multicolumn{2}{c}{ Colombia } \\
\cline { 2 - 3 } \cline { 5 - 6 } & $\mathbf{2 0 0 0 - 2 0 0 2}$ & $\mathbf{2 0 1 3 - 2 0 1 5}$ & & $\mathbf{2 0 0 0 - 2 0 0 2}$ & $\mathbf{2 0 1 3 - 2 0 1 5}$ \\
\hline Ciertas enfermedades infecciosas y parasitarias & 0,9 & 0,7 & & 0,4 & 0,2 \\
Tumores (neoplasias) & 2,2 & 1,9 & & 2,2 & 1,6 \\
Enfermedades del sistema circulatorio & 4,5 & 3,0 & & 6,8 & 4,1 \\
Enfermedades del sistema respiratorio & 0,7 & 1,1 & & 0,5 & 0,4 \\
Enfermedades del sistema digestivo & 0,2 & 0,2 & & 0,4 & 0,3 \\
Enfermedades del sistema genitourinario & 0,5 & 0,5 & & 0,3 & 0,3 \\
Restantes causas (1) & 0,1 & 0,1 & & 0,1 & 0,1 \\
Total & $\mathbf{9 , 2}$ & $\mathbf{7 , 5}$ & & $\mathbf{1 0 , 8}$ & $\mathbf{7 , 1}$ \\
\hline
\end{tabular}

Fuente: Elaboración propia con base en información proveniente de la OMS y la División de Población de la ONU.

(1) Esta categoría comprende causas cuyos valores equivalen, individualmente, a menos de 1 por 1000 habitantes. 
Finalmente, y como ya se comentara, aunque a partir de los 75 años de edad la lista de causas de muerte sensibles a la atención de la salud se reduce considerablemente en términos del volumen de causas contemplado (ver Cuadro 1 del Anexo) y el nivel de muertes atribuidas a este grupo de causas en esta población es manifiestamente inferior en comparación con el de la mortalidad de las personas de 60 a 74 años (Tabla 2), vale mencionar algunas cuestiones en relación con su composición. Concretamente, que la mortalidad atribuida a incidentes ocurridos al paciente durante la atención médica y quirúrgica acumula la mayor proporción de las defunciones en este grupo de edad: más del $90 \%$ en Argentina con independencia del trienio y, en Colombia, cerca del $80 \%$ en el trienio 2000-2002 y cerca del 65\% en el trienio 2013-2015. Asimismo, que la TM vinculada se mantiene estable en ambos países con valores inferiores a 0,3 por 1000 habitantes.

\section{Discusión}

A medida que envejecen, las personas ven reducidas gradualmente sus capacidades físicas y mentales, lo que aumenta su riesgo de contraer enfermedades y, por lo tanto, la probabilidad de muerte. Aunada a esta condición biológica, las personas mayores suelen ser, con frecuencia, víctimas de abandono y discriminación en razón de la edad, hecho que atenta contra el goce pleno de sus derechos, entre ellos el derecho a la salud (GUERRERO; YÉPEZ, 2015).

Esto último amerita que los Estados que adhieren a las convenciones de derechos humanos y que, por lo tanto, se comprometen a asegurar el acceso a la atención sanitaria oportuna y de calidad «para todas las personas de todas las edades» (ODS 3) (ONU, 2015) se ocupen con énfasis de que los servicios y las prestaciones dispuestos para el cuidado de la salud lleguen convenientemente a las personas mayores, en tanto población especialmente vulnerable a sufrir discriminación en el ejercicio de sus derechos. Tal es el caso de Argentina y Colombia, países que si bien han hecho esfuerzos en este sentido evidencian desafíos para garantizar el acceso a la atención de la salud a todas las personas de sesenta años y más, en algunos casos, compartidos y, en otros, distintos.

Estas similitudes y diferencias se desprenden de los resultados de este trabajo. Entre los desafíos en común se observa la necesidad de que ambos países redoblen los esfuerzos para continuar con la reducción de la mortalidad de la población en cuestión por causas sensibles a la atención de la salud (como indicador del acceso a los servicios de salud comprometidos a nivel internacional), más allá de los logros concretados hasta el momento. Así también, la necesidad de poner mayor énfasis en la reducción de la mortalidad masculina por estas causas, a partir de presentar niveles comparativamente mayores a los femeninos en los dos países. Finalmente, surge la necesidad de prestar mayor atención a las personas de edad más avanzada, habida cuenta de que los niveles de mortalidad crecen con la edad y alcanzan un máximo en la población de 70 a 74 años.

En cuanto a las diferencias, y más allá de las limitaciones de las fuentes de datos utilizadas (DEL POPOLO, 2000; BAY; ORELLANA, 2007; BAY, 2012; RIBOTTA, 2014; CELADE-CEPAL, 
2015; VILLARROEL-CÁRDENAS, 2018), los resultados sugieren que Argentina presentaría mayores desafíos para reducir el nivel de muertes por causas potencialmente tratables en términos generales, en la medida en que parte de una TM menor a la de Colombia y que esta asume un valor levemente superior al final del período estudiado. Esta dinámica deriva de una reducción de la mortalidad con menor intensidad en el primer caso.

En este contexto, cabe preguntarse acerca de los factores que podrían contribuir a explicar las diferencias encontradas y, a su vez, dar luz a posibles vías de acción para continuar, en ambos casos, con la reducción de muertes susceptibles de ser contrarrestadas mediante prestaciones concretas de salud. Los resultados de la ENFR de Argentina y la ECV de Colombia permiten plantear algunas aproximaciones en este sentido al señalar que aunque la proporción de personas de 65 años y más que no consultan al médico cuando necesitan asistencia de salud ${ }^{7}$ tiende a disminuir en los dos países, es menor en el caso colombiano. En efecto, en Argentina este indicador varía de $12 \%$ a 7,1\%, entre 2005 y 2013, mientras que, en Colombia lo hace de 3,8\% a 2,8\%, entre 2003 y 2013.

La consideración de los motivos de no consulta médica también aporta elementos para el despliegue de acciones tendientes a superar esta limitación en sentido universal. Los dos relevamientos referidos indican que los motivos más comunes son la «falta de importancia atribuida al cuadro clínico» y «el tiempo requerido para la obtención de turnos médicos y la realización de los trámites necesarios para efectivizarlos», coincidiendo con conclusiones de estudios previos hechos en ambos países (AYALA-GARCÍA, 2014; GAVIGLIO, 2014; ODSA, 2017). También se destaca la «carencia del dinero necesario para la consulta» (AYALA-GARCÍA, 2014), aunque este motivo tiende a presentarse cada vez con menor frecuencia, probablemente debido al incremento de la proporción de personas de 65 años y más con obra social, que asciende de $88,2 \%$ a 95,5\% en Argentina y de $73,6 \%$ a $96,2 \%$ en Colombia, de acuerdo a los relevamientos procesados. ${ }^{8}$

Más allá del incremento en la proporción de personas mayores con cobertura de salud en ambos países, cabe reflexionar acerca del estado y la calidad de las prestaciones ofrecidas en cada caso (CANO; GIRALDO; FORERO, 2016; TISNÉS; SALAZAR-ACOSTA, 2016; YÉPEZ-CHAMORRO; RICAURTE-CEPEDA; JURADO, 2018), sobre todo en Argentina, donde los indicadores analizados son comparativamente inferiores pero con trayectorias que denotan menores avances en la reducción de la mortalidad por las causas de interés. Además, merecen atención los problemas derivados de la no consulta en ambos países, entre los que figura especialmente la tendencia creciente a la automedicación (COLOMBIA, 2011; CASASVÁSQUEZ; ORTIZ-SAAVEDRA; PENNY-MONTENEGRO, 2016; COLOMBIA, 2017; CIS, 2019).

\footnotetext{
$\overline{7}$ Al igual que otros indicadores provenientes de la ENFR y la ECV, este indicador se presenta para la población de 65 años y más en función de los grupos de edad que considera el diseño de la ENFR, calibrados convenientemente en razón de limitaciones propias del relevamiento (ARGENTINA, 2005a, 2005b).

8 Esta lectura amerita ciertos recaudos, pues se ha demostrado, por ejemplo, que en Colombia existe una inequitativa distribución de la oferta de prestadores de servicios de salud, lo que imposibilita el acceso equitativo a la atención médica en todo el territorio nacional (AYALA-GARCÍA, 2014).
} 
En cuanto al acceso a las distintas prestaciones de salud, los resultados de la ENFR muestran, en los últimos años, un aumento de la proporción de personas mayores que se realizan controles de la presión arterial y el colesterol, ambas prácticas que colaboran ampliamente con la detección temprana de enfermedades cardiovasculares, aumentando la probabilidad de éxito de los tratamientos emprendidos a tales efectos (CARBAJAL, 2013). La ELPS, por su parte, acusa que más del $80 \%$ de las personas de 65 años y más con problemas de hipertensión arterial, cerebrovasculares y cardíacos en general está en tratamiento (PÉREZ-QUINTERO et al., 2014), cuestión fundamental para la reducción de la mortalidad prematura por estas causas que, además, explicaría su descenso. Como contrapartida, esta encuesta también revela que las personas que necesitan de tratamientos de este tipo y no logran acceder a ellos, no lo hacen fundamentalmente porque «no lo consideran necesario» o bien «dada la falta de dinero».

En otro orden, la ENFR señala un incremento de la proporción de mujeres mayores argentinas que se realizan mamografías y de las que acceden al Papanicolaou, dos indicadores ligados a la reducción de muertes por tumores de mama y de cuello uterino, respectivamente (GALANTE et al., 2015; ARGENTINA, 2005a, 2005b, 2015). Sin embargo, los valores que estos alcanzan en 2013 (por debajo del $45 \%$ y un tanto inferiores a los de Colombia según la ELPS), junto con la baja proporción de personas de 50 a 75 años que declararon haberse hecho al menos alguna vez un estudio de rastreo de cáncer de colon (25\%) dejan en evidencia nuevos desafíos para universalizar el acceso a los servicios de salud, más allá de las acciones llevadas a cabo desde programas estatales creados específicamente para abordar estas problemáticas (Programa Nacional de Cáncer de Mama, Programa de Prevención de Cáncer Cervicouterino, Programa Nacional de Prevención y Detección Temprana del Cáncer Colorrectal, todos de relativa juventud, creados desde el Ministerio de Salud de Argentina con posterioridad a 2010) (INC, 2016).

Por su parte, la ELPS aporta, para Colombia, información sobre la proporción de hombres que se han realizado alguna vez el examen de próstata (esencial para abordar oportunamente los tumores con esta localización) y la proporción de personas con cáncer que está en tratamiento. La magnitud de estos indicadores (cercana a $40 \%$ y $80 \%$, en ese orden) apunta también la presencia de retos para lograr el acceso universal a las prácticas de diagnóstico y tratamiento (HENRÍQUEZ; DE VRIES, 2017), ya que entre los motivos más frecuentes de no acceso se encuentran la falta de dinero y de confianza en el sistema para dar respuesta adecuada a los distintos problemas de salud (AYALAGARCÍA, 2014).

Otros esfuerzos de los Estados, que se asociarían a la reducción de la mortalidad por determinadas enfermedades infecciosas y parasitarias, incluyen, por ejemplo, las acciones ejecutadas en Argentina desde el Programa Nacional de Lepra (OPS, 2011) y los programas de inmunizaciones en todo el territorio nacional. Entre estos últimos se destaca 
la ampliación del calendario oficial de vacunación, con dosis específicas de vacunas para personas mayores como una de las principales vías de prevención9 (ARGENTINA, s.f.).

De igual manera, merecen destacarse las acciones desarrolladas en Colombia para combatir las enfermedades respiratorias. Estas se sintetizan, por ejemplo, en la proporción de personas mayores con problemas de asma, enfisema y enfermedad pulmonar obstructiva crónica (EPOC) que reciben tratamiento cercana al $84 \%$ según la ELPS. Sin embargo, logros como estos son contrarrestados al indagar acerca de los motivos por los cuales personas diagnosticadas no acceden a tratamientos, apareciendo, nuevamente, entre los más frecuentes, «la falta de importancia asignada al problema» y la «falta de dinero para el tratamiento» (AYALA-GARCíA, 2014).

Más allá de las prácticas preventivas y de tratamiento que se han reforzado con el tiempo, no pueden dejar de referirse aquellos aspectos que hacen a los estilos de vida de las personas mayores, impactando negativamente sobre su salud, aumentando el riesgo de muerte prematura y sobre los cuales los dos países deberían hacer especial foco para contrarrestar la mortalidad por las causas analizadas (sobre todo para las causas con tendencia al ascenso). Estos factores comprenden, por ejemplo, el consumo de tabaco (la ENFR acusa un aumento de la proporción de personas mayores fumadoras y exfumadoras, hecho que contribuiría a explicar en cierta medida el aumento de las muertes por neumonía) (KOJIMA et al., 2018), el sobrepeso y la obesidad (esta última, también creciente en Argentina) (VIEGO; TEMPORELLI, 2011; COLOMBIA, 2018), y el bajo nivel de actividad física en la población estudiada (también creciente en Argentina y cercano al $70 \%$ en Colombia) (FUNDACIÓN NAVARRO VIOLA, 2018).

Según el Instituto para la Métrica y Evaluación de la Salud (IHME, por sus siglas en inglés), entre 2000 y 2015, la influencia de factores conductuales que hacen a estilos de vida no saludables (fumar, presentar sobrepeso y realizar nula o escasa actividad física, entre otros) es comparativamente mayor en Argentina (IHME, s.f.a). Esta cuestión, que explicaría, en parte, la reducción menos acelerada de la mortalidad por causas potencialmente tratables en este país (teniendo en cuenta que estos factores favorecen la aparición en enfermedades al tiempo que atentan contra el éxito de cualquier tratamiento) se visualiza, por ejemplo, en la variación de la esperanza de vida saludable ${ }^{10}$ de la población de 60 a 64 años de ambos países durante el período referido: creciente de 15,8 a 16,5 años en Argentina y de 17,4 a 19,8 años en Colombia (IHME, s.f.b).

Cabe agregar que la situación empeora cuando se considera solamente a los hombres, en tanto mejora si se asocia exclusivamente a las mujeres (IHME, s.f.b).

\footnotetext{
9 El descenso de la mortalidad por causas infecciosas y parasitarias, asociado a mejoras en las condiciones materiales de vida, está en consonancia con el proceso de transición epidemiológica. A grandes rasgos, este proceso implica cambios en el perfil de la morbimortalidad de una población, con una estructura de muertes inicial en la que predominan las causas referidas y una estructura de muertes final donde son más frecuentes las enfermedades crónico-degenerativas y las causas externas. Para más información, consultar FRENK et al. (1991).

10 La esperanza de vida saludable se define a partir del número de años que se espera una persona de determinada edad viva con buen estado de salud, teniendo en cuenta los patrones de mortalidad y discapacidad vigentes en la población a la que pertenece (IHME, s.f.a).
} 


\section{Conclusiones}

Aunque en las últimas décadas Argentina y Colombia redujeron la mortalidad por causas sensibles en la atención de la salud en la población de sesenta años y más, se evidencian algunos desafíos para continuar con esta tendencia en el futuro. Estos desafíos se asocian a una mayor mortalidad en hombres y a mayor edad (esta alcanza un máximo en la población de 70 a 74 años), sobre todo en el caso argentino, donde la TM para este grupo de causas consigue reducirse en menor medida (más allá de que involucra, comparativamente, una menor proporción de muertes en el total de muertes a nivel nacional) a la vez que aumenta la TM asociada a algunas causas en particular.

Superar estos desafíos exige redoblar los esfuerzos en ambos casos, sobre todo en lo que atañe a la disponibilidad de prestaciones de prevención y tratamiento (principalmente para quienes menos recursos tienen) y su acceso efectivo. Así también, en lo concerniente a la remoción de barreras que aparecen ante la falta de confianza en el sistema y la falta de importancia que se asigna a cuestiones relacionadas con la salud por parte de la población adulta mayor.

Esto último señala la necesidad de concretar acciones más integrales en pos de revalorizar la vejez como etapa de la vida que transitan aquellos hombres y mujeres que más experiencias han acumulado en el presente de cualquier sociedad. No por envejecer una persona deja de ser persona ni de tener los derechos que los Estados se comprometen a garantizar universalmente cuando adhieren a acuerdos internacionales que los reconocen.

\section{Referencias}

ARGENTINA. Honorable Cámara de Diputados de la Nación Argentina. Proyecto de ley. Expediente 2481-D-2019. Jerarquía constitucional de la Convención Interamericana sobre Protección de los Derechos Humanos de las Personas Mayores. Buenos Aires: Senado y Cámara de Diputados, 2019. Disponible en: https://www.hcdn.gob.ar/proyectos/proyecto.jsp?exp=2481-D-2019. Acceso en: 28 ene. 2020.

ARGENTINA. INDEC - Instituto Nacional de Estadísticas y Censos; MS - Ministerio de Salud de la Nación. Tercera Encuesta Nacional de Factores de Riesgo para Enfermedades no Transmisibles. Argentina 2013. Buenos Aires: Indec, 2015.

ARGENTINA. INDEC - Instituto Nacional de Estadísticas y Censos; MS - Ministerio de Salud de la Nación. Encuesta Nacional de Factores de Riesgo 2013. Documento para la utilización de la base de datos usuario. Buenos Aires: INDEC y MS, 2014.

ARGENTINA. INDEC - Instituto Nacional de Estadísticas y Censos; MS - Ministerio de Salud de la Nación. Encuesta Nacional de Factores de Riesgo 2005. Documento para la utilización de la base de datos usuario. Buenos Aires: INDEC y MS, 2005a.

ARGENTINA. MS - Ministerio de Salud de la Nación. Encuesta Nacional de Factores de Riesgo 2005. Informe de resultados. Versión breve. Buenos Aires: MS, 2005b.

ARGENTINA. MS - Ministerio de Salud de la Nación. Calendario Nacional de Vacunación. Buenos Aires, s.f. Disponible en: http://www.msal.gob.ar/images/stories/ryc/ graficos/0000001287cnt-2018-07_flyer-calendario-vacunacion.pdf. Acceso: 02 jun. 2019. 
AYALA-GARCÍA, J. La salud en Colombia: más cobertura pero menos acceso. Cartagena: Banco de la República, 2014. (Documentos de Trabajo sobre Economía Regional).

BAY, G. Reflexiones sobre las estimaciones y proyecciones de población en América Latina: innovaciones metodológicas y dificultades para implementarlas. In: CAVENAGHI, S. Estimaciones y proyecciones de población en América Latina: desafíos de una agenda pendiente. Rio de Janeiro: Alap, 2012. p. 51-86. (Serie e-Investigaciones, n. 2).

BAY, G.; ORELLANA, H. La calidad de las estadísticas vitales en la América Latina (versión preliminar para discusión). Taller de expertos en el uso de estadísticas vitales: alcances y limitaciones. Santiago de Chile: Cepal, 2007.

CANO, S. M.; GIRALDO, A.; FORERO, C. Concepto de calidad en salud: resultado de las experiencias de la atención, Medellín, Colombia. Revista Facultad Nacional de Salud Pública, v. 34, n. 1, p. 48-53, 2016.

CARBAJAL, H. Situación de la hipertensión arterial en Argentina. Hipertensión y Riesgo Vascular, v. 30, n. 3, p. 101-106, 2013.

CASAS-VÁSQUEZ, P.; ORTIZ-SAAVEDRA, P.; PENNY-MONTENEGRO, E. Estrategias para optimizar el manejo farmacológico en el adulto mayor. Revista Peruana de Medicina Experimental y Salud Pública, v. 33, n. 2, p. 335-341, 2016.

CELADE - Centro Latinoamericano y Caribeño de Demografía/Cepal - Comisión Económica para América Latina y el Caribe. Evaluaciones e indicadores de cobertura y calidad: experiencias regionales. Taller sobre principios y recomendaciones para un sistema de estadísticas vitales, revisión 3, para países de América del Sur. Santiago de Chile, 9 al 12 de noviembre de 2015. Disponible en: https://unstats.un.org/unsd/demographic/meetings/wshops/Chile/2015/docs/ Session13-CELADE.pdf. Acceso en: 15 abr. 2019.

CEPAL - Comisión Económica para América Latina y el Caribe. Consenso de Montevideo sobre Población y Desarrollo. Montevideo: Cepal, 2013.

CIS - Centro de Investigaciones Sociales. La Salud y el uso de medicamentos. Buenos Aires: Fundación UADE; Voices! Research and Consultancy, 2019. (Informes de Opinión Pública CIS UADE-VOICES!, año 2019, n. 1). Disponible en: https://www.uade.edu.ar/upload/CIS/Informe\%20 CIS\%202019\%20n.\%201\%20\%20Salud\%20y\%20Uso\%20de\%20Medicamentos\%20\%20-\%20 ISSN\%202618-2173.pdf. Acceso en: 10 oct. 2019.

COLOMBIA. Senado de la República de Colombia. Aprobado proyecto de ley que busca proteger los derechos humanos del adulto mayor. Bogotá: Senado de la República de Colombia, 2019. Disponible en: http://www.senado.gov.co/index.php/prensa/lista-de-noticias/13senadores/342-aprobado-en-primer-debate-proyecto-de-ley-que-busca-proteger-los-derechoshumanos-de-las-personas-mayores. Acceso en: 28 ene. 2020.

COLOMBIA. MINSALUD - Ministerio de Salud y Proteccion Social et al. Encuesta Nacional de Situación Nutricional (ENSIN 2015). Nota de política. Bogotá: Prosperidad Social, 2018. Disponible en: http://www.prosperidadsocial.gov.co/temporales/Encuesta\%20Nacional\%20 de\%20la\%20Situacio\%CC\%81n\%20Nutricional\%20-\%20ENSIN\%202015.pdf. Acceso en: 10 oct. 2019.

COLOMBIA. PROFAMILIA; MINSALUD - Ministerio de Salud y Protección Social. Encuesta Nacional de Demografía y Salud. Colombia 2015. Tomo 1. Bogotá: MINSALUD, 2017.

COLOMBIA. PROFAMILIA; MPS - Ministerio de Protección Social. Encuesta Nacional de Demografía y Salud. Colombia 2010. Bogotá: MPS, 2011.

COLOMBIA. Asamblea Nacional Constituyente. Constitución Política de Colombia. Bogotá, 1991. 
DANE - Departamento Administrativo Nacional de Estadística. Ficha Metodológica Encuesta Nacional de Calidad de Vida. Mayo 2019. Bogotá: DANE, 2019. Disponible en: http://www.dane.gov.co/files/ investigaciones/fichas/calidad-de-vida/DSO-ECV-FME-001-V7.pdf. Acceso en: 05 jul. 2019.

DANE - Departamento Administrativo Nacional de Estadística. Encuesta Longitudinal de Protección Social (ELPS). Año 2012. Resultados Definitivos. Bogotá: DANE, 2014. Disponible en: https://www. dane.gov.co/files/investigaciones/ELPS/Bol_ELPS_2012.pdf. Acceso en: 13 de jul. 2019.

DEL POPOLO, F. Los problemas en la declaración de la edad en la población adulta mayor en los censos. Santiago de Chile: CELADE/CEPAL, 2010.

FUNDACIÓN NAVARRO VIOLA. La actividad física en las personas mayores: guía para promover un envejecimiento activo. 1. ed. Ciudad Autónoma de Buenos Aires: Fundación Navarro Viola; Fundación Interamericana del Corazón Argentina, 2018.

GAVIGLIO, A. Opinión sobre salud y atención de salud del adulto mayor en el conurbano bonaerense y gran La Plata. Tesis (Maestría en Salud Pública, Orientación en Sistemas de Salud) - Facultad de Ciencias Médicas, Universidad Nacional de La Plata, La Plata, 2014. Disponible en: http://sedici.unlp.edu.ar/bitstream/handle/10915/38699/Documento_completo_. pdf? sequence=1\&isAllowed=y. Acceso en: 9 oct. 2019.

GUERRERO, N.; YÉPEZ, M. C. Factores asociados a la vulnerabilidad del adulto mayor con alteraciones de salud. Universidad y Salud, v. 17, n. 1, p. 121-131, 2015.

INHME - Institute for Health Metrics and Evaluation. GBD Compare | Viz Hub. Seattle: IHME, s.f.a. Disponible en: https://vizhub.healthdata.org/gbd-compare/. Acceso en: 30 ene. 2020.

INHME - Institute for Health Metrics and Evaluation. Terms Defined. Seattle: IHME, s.f.b. Disponible en: http://www.healthdata.org/terms-defined. Acceso en: 30 ene. 2020.

INC - Instituto Nacional del Cáncer. Vigilancia epidemiológica del cáncer. Análisis de situación de salud por cáncer. Argentina, 2016. Un aporte para la toma de decisiones en salud pública basadas en información. Buenos Aires: Ministerio de Salud, 2016.

FRENK, J. et al. La transición epidemiológica en América Latina. Boletín de la Oficina Sanitaria Panamericana, v. 111, n. 6, p. 485-496, 1991.

GALANTE, M. et al. Principales resultados de la tercera Encuesta Nacional de Factores de Riesgo de Enfermedades no Transmisibles en Argentina. Revista Argentina de Salud Pública, v. 6, n. 24, p. 22-29, 2015.

HENRÍQUEZ, G.; DE VRIES, E. El efecto del envejecimiento para la carga de cáncer en Colombia: proyecciones para las primeras cinco localizaciones por departamento y sexo en Colombia, 2020 y 2050. Revista Colombiana de Cancerología, v. 21, n. 2, p. 104-112, 2017.

KOJIMA, G. et al. Does current smoking predict future frailty? The English longitudinal study of ageing. Age and Ageing, v. 47, n. 1, p. 126-131, 2018.

ODSA - Observatorio de la Deuda Social en Argentina. Las condiciones de salud de las personas mayores. Sus aspectos más críticos. Buenos Aires: Pontificia Universidad Católica Argentina (UCA), 2017.

OEA - Organización de los Estados Americanos. Convención Interamericana sobre la Protección de los Derechos Humanos de las Personas Mayores. Washington, D.C.: OEA, 2015.

OEA - Organización de los Estados Americanos. Convención Interamericana sobre la Protección de los Derechos Humanos de las Personas Mayores. Estado de Firmas y Ratificaciones. Washington, D.C.: OEA, 2015. Disponible en: http://www.oas.org/es/sla/ddi/tratados_ multilaterales_interamericanos_A-70_derechos_humanos_personas_mayores_firmas.asp. Acceso en: 28 ene. 2020. 
OMS - Organización Mundial de la Salud. Envejecimiento. Disponible en: https://www.who.int/ topics/ageing/es/. Acceso en: 17 marzo 2019.

ONU - Organización de las Naciones Unidas. Transformar nuestro mundo: la Agenda 2030 para el Desarrollo Sostenible. Resolución aprobada por la Asamblea General el 25 de septiembre de 2015. Nueva York: ONU, 2015.

ONU - Organización de las Naciones Unidas. Pacto Internacional sobre Derechos Económicos, Sociales y Culturales. Nueva York: NU, 1966.

ONU - Organización de las Naciones Unidas. Declaración Universal de Derechos Humanos. París: ONU, 1966.

OPS - Organización Panamericana de la Salud - Unidad de Información y Análisis de Salud. Glosario de indicadores básicos de la OPS. Iniciativa regional de datos básicos en salud. Washington D.C.: OPS, 2015.

OPS - Organización Panamericana de la Salud. Boletín Epidemiológico, v. 24, n. 4, 2003.

OPS - Organización Panamericana de la Salud. Plan Estratégico de la Organización Panamericana de la Salud 2014-2019. “En pro de la salud: Desarrollo sostenible y equidad”. Versión modificada en septiembre de 2014. Washington D.C.: OPS, 2014.

OPS - Organización Panamericana de la Salud. La OPS/OMS colabora con la Argentina para eliminar la lepra. 13 Septiembre 2011. Disponible en: https://www.paho.org/arg/index. php?option=com_content \&view=article\&id=790:la-ops-oms-colabora-argentina-eliminarlepra\&ltemid=268. Acceso en: 20 jun. 2018.

PÉREZ-QUINTERO, C. et al. Evaluación de un programa de atención de la hipertensión arterial, según normatividad vigente en Colombia. Duazary, v. 11, n. 1, p. 14-21, 2014.

RIBOTTA, B. Exactitud de la información sobre la causa básica de muerte en América Latina. In: VI CONGRESO DE LA ASOCIACIÓN LATINOAMERICANA DE POBLACIÓN. Anais [...]. Lima: ALAP, 12 al 15 de agosto de 2014. Disponible en: http://www.alapop.org/Congreso2014/DOCSFINAIS_PDF/ ALAP_2014_FINAL323.pdf. Acceso en: 23 ene. 2020.

THE DHS PROGRAM. Demographic and Health Surveys. [S.f.]. Disponible en: https://dhsprogram. com/. Acceso en: 27 ene. 2020.

TISNÉS, A.; SALAZAR-ACOSTA, L. Envejecimiento poblacional en Argentina: ¿qué es ser un adulto mayor en Argentina? Una aproximación desde el enfoque de la vulnerabilidad social. Papeles de Población, n. 88, p. 209-236, 2016.

VIEGO, V.; TEMPORELLI, K. Sobrepeso y obesidad en Argentina. Un análisis basado en técnicas de econometría espacial. Estudios de Economía Aplicada, v. 29, n. 3, p. 1-25, 2011.

VILLARROEL-CÁRDENAS, M. Algunos indicadores de calidad de la información de las estadísticas vitales. In: TALLER REGIONAL SOBRE EL USO, COMPLETITUD Y CALIDAD DE LAS ESTADÍSTICAS DE NACIMIENTOS Y DEFUNCIONES. FORTALECIENDO LOS REGISTROS ADMINISTRATIVOS CON MIRAS AL SEGUIMIENTO DE LA AGENDA 2030 Y DEL CONSENSO DE MONTEVIDEO. Anais [...]. Santiago de Chile: CELADE/CEPAL, 10 al 12 de septiembre de 2018. Disponible en: https://www.cepal.org/ sites/default/files/presentations/sesion7_villarroel.pdf. Acceso en: 23 ene. 2020.

YÉPEZ-CHAMORRO, M. C.; RICAURTE-CEPEDA, M.; JURADO, D. M. Calidad percibida de la atención en salud en una red pública del municipio de Pasto, Colombia. Universidad y Salud, v. 20, n. 2, p. 97-110, 2018 


\title{
Sobre los autores
}

Eleonora Rojas Cabrera es Doctora en Demografía por la Universidad Nacional de Córdoba (UNC). Investigadora adjunta del Consejo Nacional de Investigaciones Científicas y Técnicas (CONICET) con sede de trabajo en el Centro de Investigaciones y Estudios sobre Cultura y Sociedad (CIECS), unidad dependiente del CONICET y la UNC, Córdoba, Argentina.

Andrés Peranovich es Doctor en Demografía por la Universidad Nacional de Córdoba (UNC). Investigador adjunto del Consejo Nacional de Investigaciones Científicas y Técnicas (CONICET) con sede de trabajo en el Centro de Investigaciones y Estudios sobre Cultura y Sociedad (CIECS), unidad dependiente del CONICET y la UNC, Córdoba, Argentina.

Doris Cardona Arango es Doctora en Demografía por la Universidad Nacional de Córdoba. Docente investigadora de la Universidad CES, Medellín, Colombia.

Douglas Lizcano Cardona es Magíster en Epidemiología por la Universidad CES. Estudiante de Doctorado en Epidemiología y Bioestadística en la Universidad CES, Medellín, Colombia.

\section{Dirección para correspondencia}

\author{
Eleonora Rojas Cabrera \\ X5000HRV - Córdoba, Argentina \\ Andrés Peranovich \\ X5000HRV - Córdoba, Argentina \\ Doris Cardona Arango \\ Universidad CES \\ Calle 10A \#22-04, El Poblado \\ 050022 - Medellín, Colombia \\ Douglas Lizcano Cardona \\ Universidad CES \\ Calle 10A \#22-04, El Poblado \\ 050022 - Medellín, Colombia.
}

Centro de Investigaciones y Estudios sobre Cultura y Sociedad (CIECS) - Consejo Nacional de Investigaciones Científicas y Técnicas (CONICET) y Universidad Nacional de Córdoba (UNC)

Avenida Valparaíso s/n, Ciudad Universitaria

Centro de Investigaciones y Estudios sobre Cultura y Sociedad (CIECS) - Consejo Nacional de Investigaciones Científicas y Técnicas (CONICET) y Universidad Nacional de Córdoba (UNC) Avenida Valparaíso s/n, Ciudad Universitaria

\section{Resumo}

O exercício do direito à saúde em pessoas idosas na Argentina e na Colômbia: uma abordagem baseada na análise da mortalidade por causas sensíveis aos cuidados de saúde no século XXI

Tendo em vista que a Argentina e a Colômbia reconhecem a saúde enquanto um direito essencial e comprometem-se, entre outras questões, a fornecer benefícios à saúde para garantir seu exercício sem discriminação, propõe-se investigar, comparativamente, os desafios enfrentados para o cumprimento desse compromisso para pessoas com 60 anos ou mais. Para esse fim, as taxas de mortalidade por causas consideradas sensíveis aos cuidados de saúde de acordo com país, sexo e idade, com base em informações da Organização das Nações Unidas, são calculadas 
e analisadas para os períodos 2000-2002 e 2013-2015, sendo que proporções específicas são calculadas em pesquisas oficiais de cada país. Os resultados mostram, nos dois países e por todas as causas referidas, uma maior mortalidade em homens, aumentando com a idade de 74 anos e com tendência a declinar, principalmente na Colômbia. Uma análise mais detalhada por causas revela uma situação semelhante no último caso, ao contrário da Argentina, onde a mortalidade por doenças respiratórias aumenta. Independentemente dessas diferenças, as taxas obtidas no final do período investigado acusam, em ambos os países, a necessidade de redobrar esforços para continuar a redução da mortalidade (ou reverter seu aumento), com foco especial nos idosos que têm menos recursos e em seu valor enquanto cidadãos com direitos iguais ao resto da população.

Palavras-chave: Direitos humanos. Pessoas idosas. Acesso a serviços de saúde. Mortalidade por causas sensíveis aos cuidados de saúde. Argentina. Colômbia.

\section{Abstract}

The exercise of the right to health in older persons in Argentina and Colombia: an approach based on the analysis of mortality due to causes sensitive to health care in the XXI century

Since Argentina and Colombia recognize health as a fundamental right, and undertake, among other issues, to provide healthcare services to guarantee its exercise without discrimination, our aim is to inquire, comparatively, about the challenges these countries face in fulfilling this commitment for population aged 60 and older. Thus, mortality rates from causes considered sensitive to health care by country, sex and age are calculated and analysed for trienniums 2000 2002 and 2013-2015, based on information from the United Nations. Besides, specific proportions are calculated based on each country's official surveys. Results show, in both countries and for all groups of causes considered, a higher mortality in men, increasing with age up to 74 years and with a tendency to decline, mainly in Colombia. A more detailed analysis by causes reveals a similar situation in the latter case, unlike Argentina where mortality from respiratory diseases increases. Regardless of these differences, the rates associated to period 2013-2015 reveal, in both countries, the need to increase efforts to continue their reduction (or reverse their increase), with a special focus on those who have fewer resources and on their value as citizens with the same rights as the rest of the population.

Keywords: Human rights. Older persons. Access to health services. Mortality from causes sensitive to health care. Argentina. Colombia. 


\section{Anexo}

\section{CUADRO 1}

Lista de causas sensibles a la atención de la salud (1)

\begin{tabular}{|c|c|c|c|}
\hline $\begin{array}{l}\text { Tipo de } \\
\text { causas }\end{array}$ & $\begin{array}{l}\text { Nombre del grupo } \\
\text { de causas o causa }\end{array}$ & $\begin{array}{l}\text { Rango de } \\
\text { edad }\end{array}$ & $\begin{array}{l}\text { Códigos de } \\
\text { CIE-10 }\end{array}$ \\
\hline \multirow{15}{*}{$\begin{array}{l}\text { Ciertas } \\
\text { enfermedades } \\
\text { infecciosas y } \\
\text { parasitarias }\end{array}$} & Enfermedades infecciosas intestinales & $0-14$ & A00-A09 \\
\hline & Tuberculosis & $0-74$ & A15-A19, B90 \\
\hline & $\begin{array}{l}\text { Ciertas zoonosis bacterianas (Tularemia, Carbunco-ántrax, } \\
\text { Brucelosis, Muermo y Melioidosis, Fiebre por mordedura } \\
\text { de Rata, Erisipeloide, Otras enfermedades zoonóticas } \\
\text { bacterianas no clasificadas en otra parte) }\end{array}$ & $0-74$ & A21-A26, A28 \\
\hline & $\begin{array}{l}\text { Lepra, Infecciones debidas a otras micobacterias, } \\
\text { Listeriosis, Tétanos neonatal, Tétanos obstétrico, } \\
\text { Septicemia Estreptocócica, Otras septicemias, Otras } \\
\text { enfermedades bacterianas no clasificadas en otra parte }\end{array}$ & $0-74$ & $\begin{array}{l}\text { A30-A33, A34, } \\
\text { A40, A41, A48 }\end{array}$ \\
\hline & $\begin{array}{l}\text { Otras infecciones (Otros tétanos, Difteria, Poliomielitis } \\
\text { aguda) }\end{array}$ & $0-74$ & $A 35, A 36, A 80$ \\
\hline & Tos ferina & $0-14$ & A37 \\
\hline & $\begin{array}{l}\text { Escarlatina, Erisipela, Infección estreptocócica de sitio no } \\
\text { especificado }\end{array}$ & $0-74$ & A38, A46, A49.1 \\
\hline & $\begin{array}{l}\text { Linfogranuloma (venéreo) por clamidia, Chancro blando, } \\
\text { Granuloma inguinal, Enfermedad de transmisión sexual } \\
\text { no especificada }\end{array}$ & $0-74$ & $\begin{array}{l}\text { A55, A57, A58, } \\
\text { A64 }\end{array}$ \\
\hline & Fiebres recurrentes & $0-74$ & A68 \\
\hline & $\begin{array}{l}\text { Sarampión, Rubeola, Infección viral no especificada } \\
\text { caracterizada por lesiones de la piel y de las membranas } \\
\text { mucosas }\end{array}$ & $1-14$ & B05, B06, B09 \\
\hline & $\begin{array}{l}\text { Hepatitis aguda tipo A, Hepatitis aguda tipo B, Hepatitis } \\
\text { aguda C, Hepatitis viral crónica, Hepatitis viral sin otra } \\
\text { especificación }\end{array}$ & $0-74$ & B15-B19 \\
\hline & $\begin{array}{l}\text { Enfermedad por virus de la inmunodeficiencia humana } \\
\text { (VIH) }\end{array}$ & & B20-B24 \\
\hline & $\begin{array}{l}\text { Paludismo (malaria) debido a Plasmodium falciparum, } \\
\text { Paludismo (malaria) debido a Plasmodium vivax, } \\
\text { Paludismo (malaria) debido a Plasmodium malariae, Otro } \\
\text { paludismo (malaria) confirmado parasitológicamente, } \\
\text { Paludismo no especificado }\end{array}$ & $0-74$ & B50-B54 \\
\hline & $\begin{array}{l}\text { Esquistosomiasis, otras infecciones debidas a trematodos, } \\
\text { Equinococosis, Teniasis, Cisticercosis, } \\
\text { Otras infecciones debidas a cestodos, Oncocercosis, } \\
\text { Filariasis, Triquinosis, Anquilostomiasis y Necatoriasis, } \\
\text { Ascariasis, Strongiloidiasis, Tricuriasis, Enterobiasis, Otras } \\
\text { helmintiasis intestinales no clasificadas en otra parte, } \\
\text { Parasitosis intestinales sin otra especificación, otras } \\
\text { helmintiasis }\end{array}$ & $0-74$ & $\begin{array}{l}\text { B65-B69, B71, } \\
\text { B73-B83 }\end{array}$ \\
\hline & Celulitis & & L03 \\
\hline \multirow{6}{*}{$\begin{array}{l}\text { Tumores } \\
\text { (neoplasias) }\end{array}$} & Tumor maligno del labio & $0-74$ & $\mathrm{COO}$ \\
\hline & $\begin{array}{l}\text { Tumor maligno del estómago } \\
\text { Tumor maligno del colon, de la unión rectosigmoidea, del } \\
\text { recto y del ano y del conducto anal }\end{array}$ & $0-74$ & $\begin{array}{l}\text { C16 } \\
\text { C18-C21 }\end{array}$ \\
\hline & $\begin{array}{l}\text { Tumor maligno del hígado y de las vías biliares } \\
\text { intrahepáticas }\end{array}$ & & $\mathrm{C} 22$ \\
\hline & $\begin{array}{l}\text { Melanoma maligno de la piel } \\
\text { Otros tumores malignos de la piel }\end{array}$ & $0-74$ & $\begin{array}{l}\text { C43 } \\
\text { C44 }\end{array}$ \\
\hline & Tumor maligno de la mama (femenina solamente) & $0-74$ & C50 \\
\hline & Tumor maligno del cuello del útero & $0-74$ & C53 \\
\hline
\end{tabular}


(continuación)

\begin{tabular}{|c|c|c|c|}
\hline $\begin{array}{l}\text { Tipo de } \\
\text { causas }\end{array}$ & $\begin{array}{l}\text { Nombre del grupo } \\
\text { de causas o causa }\end{array}$ & $\begin{array}{l}\text { Rango de } \\
\text { edad }\end{array}$ & $\begin{array}{l}\text { Códigos de } \\
\text { CIE-10 }\end{array}$ \\
\hline \multirow[t]{8}{*}{$\begin{array}{l}\text { Tumores } \\
\text { (neoplasias) }\end{array}$} & $\begin{array}{l}\text { Tumor maligno del cuerpo del útero } \\
\text { Tumor maligno del útero, parte no especificada }\end{array}$ & $0-74$ & $\begin{array}{l}\text { C54 } \\
\text { C55 }\end{array}$ \\
\hline & Tumor maligno del testículo & $0-74$ & C62 \\
\hline & Tumor maligno de la vejiga urinaria & $0-74$ & C67 \\
\hline & Tumor maligno de la glándula tiroides & $0-74$ & C73 \\
\hline & Enfermedad de Hodgkin & $0-74$ & C81 \\
\hline & Leucemia & $0-44$ & C91-C95 \\
\hline & Tumores (neoplasias) in situ & $0-74$ & D00-D09 \\
\hline & Tumores (neoplasias) benignas & $0-74$ & D10-D36 \\
\hline \multirow{2}{*}{$\begin{array}{l}\text { Enfermedades } \\
\text { endócrinas, } \\
\text { nutricionales y } \\
\text { metabólicas }\end{array}$} & Trastornos de la glándula tiroides & $0-74$ & E00-E07 \\
\hline & $\begin{array}{l}\text { Diabetes mellitus } \\
\text { Síndrome de Cushing, Trastornos adrenogenitales } \\
\text { Otros trastornos de la glándula suprarrenal } \\
\text { Enfermedad del almacenamiento del glucógeno } \\
\text { Trastorno del metabolismo de la galactosa }\end{array}$ & $0-49$ & $\begin{array}{l}\text { E10-E14 E24, } \\
\text { E25 } \\
\text { E27 } \\
\text { E74.0 } \\
\text { E74.2 }\end{array}$ \\
\hline \multirow[t]{2}{*}{$\begin{array}{l}\text { Enfermedades del } \\
\text { sistema nervioso }\end{array}$} & $\begin{array}{l}\text { Meningitis bacteriana, no clasificada en otra parte } \\
\text { Meningitis debida a otras causas y a las no especificadas } \\
\text { Encefalitis, mielitis y encefalomielitis } \\
\text { Absceso y granuloma intracraneal e intrarraquídeo }\end{array}$ & $0-74$ & $\begin{array}{l}\text { G00, G03 } \\
\text { (excepto G03.0) } \\
\text { G04 } \\
\text { G06 }\end{array}$ \\
\hline & Epilepsia & $0-74$ & G40-G41 \\
\hline \multirow[t]{6}{*}{$\begin{array}{l}\text { Enfermedades } \\
\text { del sistema } \\
\text { circulatorio }\end{array}$} & $\begin{array}{l}\text { Fiebre reumática sin mención de complicación cardíaca } \\
\text { Fiebre reumática con complicación cardíaca } \\
\text { Corea reumática }\end{array}$ & $0-74$ & $100-102$ \\
\hline & Enfermedades cardíacas reumáticas crónicas & $0-74$ & $105-109$ \\
\hline & Enfermedades hipertensivas & $0-74$ & |10-|13, |15 \\
\hline & Enfermedades isquémicas del corazón & $0-74$ & $\begin{array}{l}120-125 \text { (excepto } \\
124.9 \text { y } 125.0 \text { ) }\end{array}$ \\
\hline & Enfermedades cerebrovasculares & $0-74$ & 160-169, \\
\hline & $\begin{array}{l}\text { Aterosclerosis (2) Enfermedad vascular periférica, no } \\
\text { especificada }\end{array}$ & & $\begin{array}{c}170 \\
173.9 \\
\end{array}$ \\
\hline \multirow{3}{*}{$\begin{array}{l}\text { Enfermedades } \\
\text { del sistema } \\
\text { respiratorio }\end{array}$} & $\begin{array}{l}\text { Todas las enfermedades respiratorias (excepto influenza } \\
\text { y neumonía) }\end{array}$ & $1-14$ & J00-J09, J20-J99 \\
\hline & Influenza & $0-74$ & J10-J11 \\
\hline & $\begin{array}{l}\text { Neumonía } \\
\text { Asma }\end{array}$ & $0-74$ & $\begin{array}{l}112-118 \\
\mathrm{~J} 45-146\end{array}$ \\
\hline \multirow[t]{6}{*}{$\begin{array}{l}\text { Enfermedades del } \\
\text { sistema digestivo }\end{array}$} & $\begin{array}{l}\text { Úlcera gástrica, úlcera duodenal, úlcera péptica de sitio no } \\
\text { especificado, úlcera gastroyeyunal } \\
\text { Gastritis y duodenitis }\end{array}$ & $0-74$ & $\begin{array}{l}\mathrm{K} 25-\mathrm{K} 27, \mathrm{~K} 28, \\
\mathrm{~K} 29\end{array}$ \\
\hline & Enfermedades del apéndice & $0-74$ & K35-K38 \\
\hline & Hernia & $0-74$ & $\mathrm{~K} 40-\mathrm{K} 46$ \\
\hline & Íleo paralítico y obstrucción intestinal sin hernia & $0-74$ & K56 \\
\hline & $\begin{array}{l}\text { Colelitiasis, Colecistitis, Otras enfermedades de la vesícula } \\
\text { biliar, Otras enfermedades de las vías biliares, Pancreatitis } \\
\text { aguda, Otras enfermedades del páncreas }\end{array}$ & $0-74$ & K80-K86 \\
\hline & $\begin{array}{l}\text { Trastornos del sistema digestivo consecutivos a } \\
\text { procedimientos, no clasificados en otra parte }\end{array}$ & $0-74$ & K91 \\
\hline
\end{tabular}


(continuación)

\begin{tabular}{|c|c|c|c|}
\hline $\begin{array}{l}\text { Tipo de } \\
\text { causas }\end{array}$ & $\begin{array}{l}\text { Nombre del grupo } \\
\text { de causas o causa }\end{array}$ & $\begin{array}{l}\text { Rango de } \\
\text { edad }\end{array}$ & $\begin{array}{l}\text { Códigos de } \\
\text { CIE-10 }\end{array}$ \\
\hline \multirow[t]{5}{*}{$\begin{array}{l}\text { Enfermedades } \\
\text { del sistema } \\
\text { genitourinario }\end{array}$} & $\begin{array}{l}\text { Enfermedades glomerulares, Uropatía obstructiva y por } \\
\text { reflujo, Insuficiencia renal, Cálculo del riñón y del uréter, } \\
\text { Cálculo de las vías urinarias inferiores, Cólico renal no } \\
\text { especificado, Trastornos resultantes de la función tubular } \\
\text { renal alterada, riñón contraído, no especificado, riñón } \\
\text { pequeño de causa desconocida, Uretritis no especificada, } \\
\text { Estrechez uretral }\end{array}$ & $0-74$ & $\begin{array}{l}\text { N00-N08, } \\
\text { N13, N17-N19, } \\
\text { N20, N21, N23, } \\
\text { N25-N27, N34.1, } \\
\text { N35 }\end{array}$ \\
\hline & Hiperplasia de la próstata & $0-74$ & $\mathrm{~N} 40$ \\
\hline & $\begin{array}{l}\text { Salpingitis y ooforitis, Enfermedad inflamatoria del útero, } \\
\text { excepto del cuello uterino, Enfermedad inflamatoria del } \\
\text { cuello uterino, Otras enfermedades pélvicas inflamatorias, } \\
\text { Enfermedades de la glándula de Bartholin, Otras } \\
\text { afecciones inflamatorias de la vagina y de la vulva }\end{array}$ & $0-74$ & $\begin{array}{c}\text { N70-N73, N75, } \\
\text { N76 }\end{array}$ \\
\hline & $\begin{array}{l}\text { Displasia del cuello uterino, Otros trastornos no } \\
\text { inflamatorios del cuello del útero, Otros trastornos no } \\
\text { inflamatorios de la vulva y del perineo }\end{array}$ & $0-74$ & N87, N88, N90 \\
\hline & Estrechez uretral consecutiva a procedimientos & $0-74$ & N99.1 \\
\hline \multirow{3}{*}{$\begin{array}{l}\text { Maternas y } \\
\text { perinatales }\end{array}$} & Embarazo, parto y puerperio & Todas & 000-099 \\
\hline & Ciertas afecciones originadas en el período perinatal & $0-74$ & P00-P96 \\
\hline & $\begin{array}{l}\text { Malformaciones congénitas, deformidades y anomalías } \\
\text { cromosómicas }\end{array}$ & Todas & Q00-Q99 \\
\hline Causas externas & $\begin{array}{l}\text { Incidentes ocurridos al paciente durante la atención } \\
\text { médica y quirúrgica }\end{array}$ & Todas & $\begin{array}{l}\text { Y60-Y69, } \\
\text { Y83-Y84 }\end{array}$ \\
\hline
\end{tabular}

Fuente: Elaboración propia con base en OPS (2014).

(1) Lista de causas seleccionadas y aceptadas por los países miembros de le OPS/OMS, septiembre 2013.

(2) A los códigos 170 e 173.9 se le restan $50 \%$ de las defunciones. 